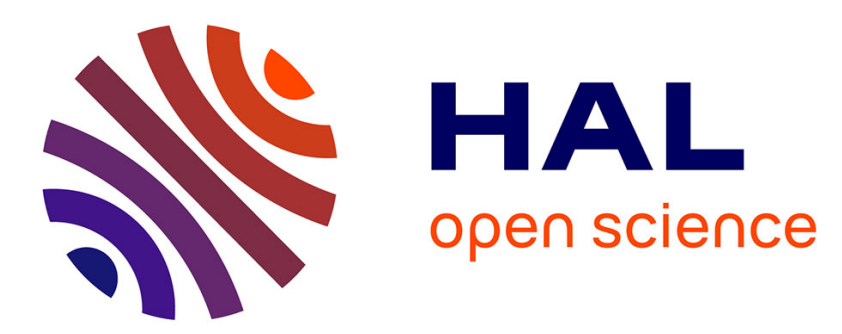

\title{
Fracture cleaning: experimental study on the unclogging process within a propped fracture under a dynamic stimulation
}

Youssef Fawaz, Christian La Borderie, Pascale Sénéchal, Antoine Jacques, Gilles Pijaudier-Cabot

\section{To cite this version:}

Youssef Fawaz, Christian La Borderie, Pascale Sénéchal, Antoine Jacques, Gilles Pijaudier-Cabot. Fracture cleaning: experimental study on the unclogging process within a propped fracture under a dynamic stimulation. 2020. hal-02897925v2

\section{HAL Id: hal-02897925 \\ https://hal.science/hal-02897925v2}

Preprint submitted on 21 Jul 2020

HAL is a multi-disciplinary open access archive for the deposit and dissemination of scientific research documents, whether they are published or not. The documents may come from teaching and research institutions in France or abroad, or from public or private research centers.
L'archive ouverte pluridisciplinaire HAL, est destinée au dépôt et à la diffusion de documents scientifiques de niveau recherche, publiés ou non, émanant des établissements d'enseignement et de recherche français ou étrangers, des laboratoires publics ou privés. 


\title{
Fracture cleaning: experimental study on the unclogging process within a propped fracture under a dynamic stimulation
}

\author{
by \\ Youssef Fawaz ${ }^{\text {a }}$, Christian La Borderie ${ }^{\mathrm{b}}$, Pascale Sénéchal ${ }^{\mathrm{c}}$, Antoine Jacques ${ }^{\mathrm{d}}$, Gilles \\ Pijaudier-Cabot ${ }^{\mathrm{a}}$ \\ a Universite de Pau et des Pays de l'Adour, E2S UPPA, CNRS, Total, LFCR, Anglet, France \\ ${ }^{\mathrm{b}}$ Universite de Pau et des Pays de l'Adour, E2S UPPA, SIAME, Anglet, France \\ ${ }^{c}$ Universite de Pau et des Pays de l'Adour, E2S UPPA, CNRS, Total, DMEX, Pau, France \\ d Total E\&P, CSTJF, Avenue Larribau, Pau, France
}

\begin{abstract}
Dynamic excitation of a clogged fracture can increase its permeability. Pressure oscillations inside the fracture are expected to flush out the fine particles blocking the flow. The objective is to improve the performance of gas and oil wells by cleaning the fractures previously generated by hydraulic fracturing as the circulation of sediments during service tend to clog them. Yet, more investigations shall be conducted to understand the mechanism better. This experimental study investigates the unclogging process of a propped fracture previously clogged, using a synthetic dynamic load. Laboratory experiments are presented. Fractures are clogged with crushed natural sand. All the permeability measurements are performed under uniaxial stress of $20 \mathrm{MPa}$ to mirror real operating conditions. After applying the dynamic load, a significant increase of the intrinsic permeability is observed. The highest recovery rate reached was $82 \%$. The influence of the proppant density, of the proppant size, and of the frequency of the dynamic signal are discussed. X-ray CT scans provide images of the fracture before and after the dynamic load has been applied. The results show that a high percentage of fines are flushed out of the fracture.
\end{abstract}

Keywords: Fracture, proppant, dynamic stimulation, waves, intrinsic permeability, unclogging Corresponding author: Youssef.fawaz@univ-pau.fr 


\section{Introduction}

The efficiency of oil and gas wells is closely related to the permeability of the reservoir system trapping hydrocarbons in the rock porosity. In order to improve their performance, hydrocarbon reservoirs are stimulated using hydraulic fracturing which consists in driving cracks in the rock mass and at the same time injecting with the fracturing fluid proppant, i.e. sand or ceramic particles which prevent crack closure upon a release of the fluid pressure. Proppant is used in order to preserve a relatively high permeability of the fracture and therefore to promote hydrocarbon extraction. During well service, however, fluids and gases cause fine particles to circulate in the fractures. These fine particles originate from the local creep collapse of the rock, precipitation of salts (present in the water that often comes with hydrocarbons), scaling which is a chemical reaction between the reservoir fluids and solids, proppant crushing, etc. These particles can adhere to the crack walls, to the proppant skeleton, and they may form clusters or aggregates which block pore throats. Along with proppant embedment which reduces the fracture opening (see e.g. Zhong et al., 2019), the presence of these clusters of fine particles results in fracture clogging, a loss of permeability of the hydraulically-driven fracture with time, and in a decrease of the hydrocarbon production with time eventually (Guerra et al., 2018). A common way to restore the fracture conductivity is to "refrac" the reservoir, which means to implement the same procedure as for the initial fracking phase in the reservoir (see e.g. Kennedy, 2015), and also possibly to add chemicals that dissolve scales.

Instead, pore pressure oscillations may be a solution in order to destabilize clusters and to restore the conductivity of fractures. This mechanism is widely used in granular flow in order to avoid the formation of arches that clog exits of silos. Some models exist (see e.g. Nicolas et al., 2018) but they are hardly applicable to propped fracture since they rely on the propagation of waves in the solid phase, without considering a fluid phase. At the laboratory scale, some scientists have found that a dynamic vibration of the fluid pressure could induce an increase of 
the permeability and improve the flow and the drainage system (see e.g. Roberts, 2005 or Candela et al., 2014). This phenomenon was also confirmed by the rise in water and oil well production following seismic events (Beresnev and Johnson, 1994). In both cases, it has been hypothesized that the fluid pressure oscillations would contribute at breaking the clusters of fine particles and put fine particles in motion so that they may be evacuated through the throats of the pore network that were clogged by clusters. This mechanism explains the observed permeability enhancement (Brodsky, 2003; Candela et al., 2014; Elkhoury et al., 2011), qualitatively at least because such assumptions could not be verified directly by experimental observations. Experiments and modelling on this topic can be found in the literature, but dealing with 1D columns tests (Zheng et al., 2014) where water and fine particles circulate in a cylindrical porous media, with application to aquifers. More recently, Liu et al. (2019) conducted a microfluidic experiment in order to see the effect of convergent flow that is commonly observed in porous materials (e.g. through throats).

The main purpose of this paper is to provide some experimental evidence of this cloggingunclogging fracture process due to oscillations of the fluid pressure inside a propped fracture. Besides the importance of understanding the major mechanisms that control this process, it is also important to question its practical feasibility, meaning how to generate and transmit dynamic vibrations (in the pore fluid) along the fracture generated in the stimulation.

Oscillations of the fluid pressure may be induced in the near well bore region by applying (electrically induced) shock waves near propped fractures (Fig. 1), similar to those used in electro-hydraulic fracturing (see e.g. Chen et al, 2012 or Pijaudier-Cabot et al. 2016). 


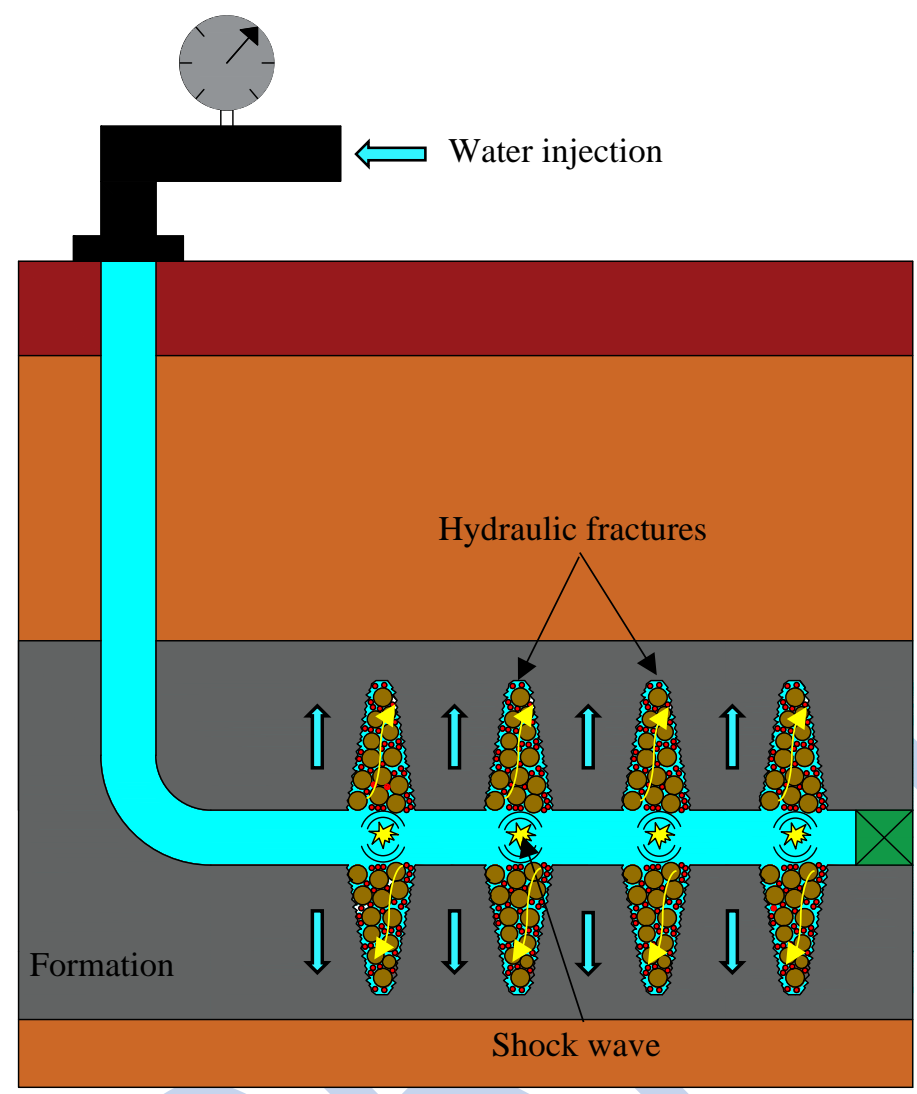

Fig. 1. Schematic description of a fractured horizontal well under water injection subjected to a dynamic stimulation (shock wave).

A major issue is then to transmit such oscillations of pressure along the hydraulically-induced fracture, with an attenuation that is as small as possible in order to promote unclogging of the largest portion of the fracture, if it occurs eventually. Varela Valdez et al. (2017) reported that the propagation of these pressure oscillations along the fracture it is indeed possible. They considered the propagation of a fluid pressure wave (FPW) in an existing crack saturated with water (Fig. 2). The fluid pressure wave was sinusoidal with an amplitude of $60 \mathrm{kPa}$ and a fixed frequency in the well. Numerical analyses concluded that FPW creates body waves and surface waves in the rock. Because surface waves are not attenuated, as opposed to body waves, they induce significant fluid pressure oscillations in the fracture far from the well (e.g. at distances beyond $100 \mathrm{~m}$ ). Also, it was observed that pressure gradients created by the surface waves are more important for the rough fractures. Therefore, it is reasonable to consider that if such 
oscillations may unclog propped fracture and promote the recovery of fracture conductivity after clogging, this stimulation technique might be effective over a large part of the propped fractures.
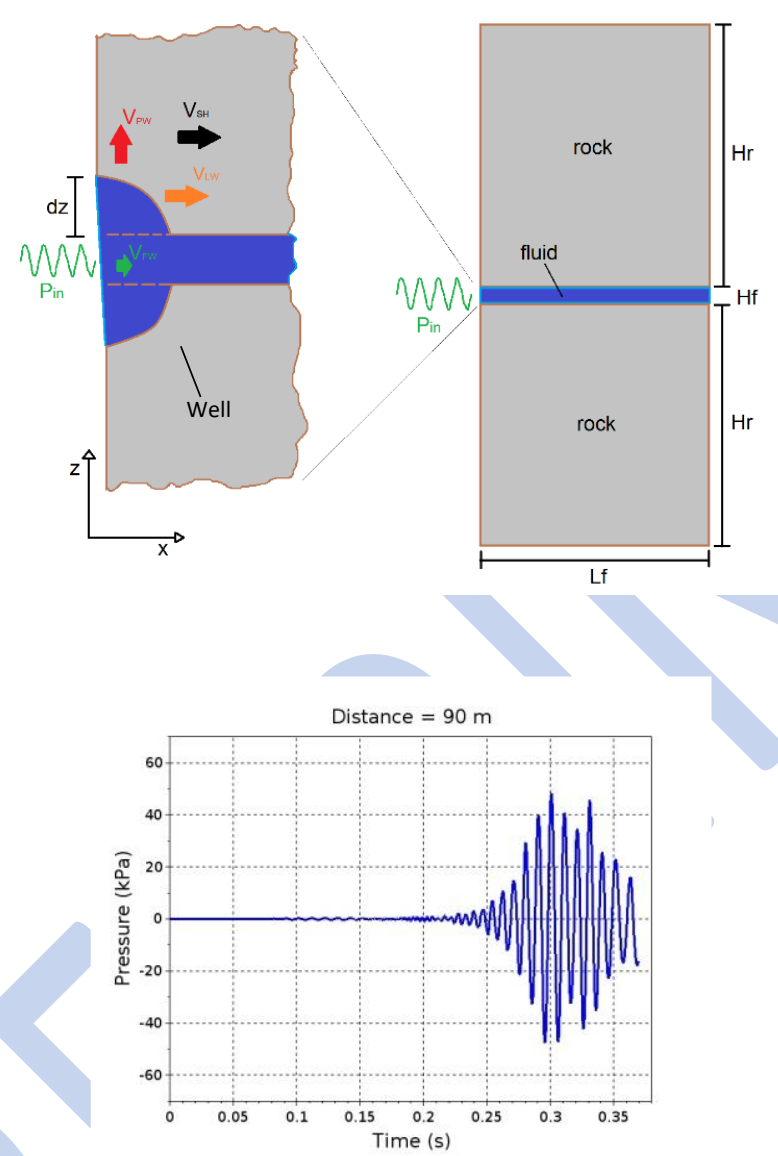

Fig. 2. Top: geometry of the numerical model where $V_{P W}=$ compression wave through the rock, $V_{S W}=$ shear wave through the rock, $V_{R W}=$ surface wave (Rayleigh wave), $V_{F W}=$ pore pressure wave, dz= deformation of the rock by the pore pressure wave, $P_{i n}=$ sinusoidal input pressure wave (amplitude $=60 \mathrm{kPa}$ ), $L_{f}=$ length of the fracture, $H_{r}=$ height of the rock below and above the fracture, $H_{f}=$ Fracture aperture; bottom: recording over time of the fluid pressure at $90 \mathrm{~m}$ from the well. After Varela Valdez et al. (2017).

The present paper reports an experimental study that will allow reproducing the effects of the propagation of a surface pressure wave in a crack previously clogged on its permeability at the laboratory scale. Section 2 presents the experimental program and the various set-ups that have been designed and implemented. Results are reported in section 3.

\section{Experimental program}

A systematic set of experiments was carried out to explore the evolution of permeability of a clogged fracture exposed to a dynamic load perpendicular to the fracture plane. The principle 
of the test is to isolate a part of the fracture shown in Fig. 2 and to apply a dynamic oscillation of the fracture surfaces, representative of a surface pressure wave propagating on them, while at the same time a fluid at constant flow rate circulates in the fracture. The set-up is schematized in Fig. 3. Its principle is quite similar to the tests performed by Guerra et al. (2018) dedicated to the measurement of fracture conductivity and the effect of flowback water for eagle Ford fractured shales, with a different aim, however.

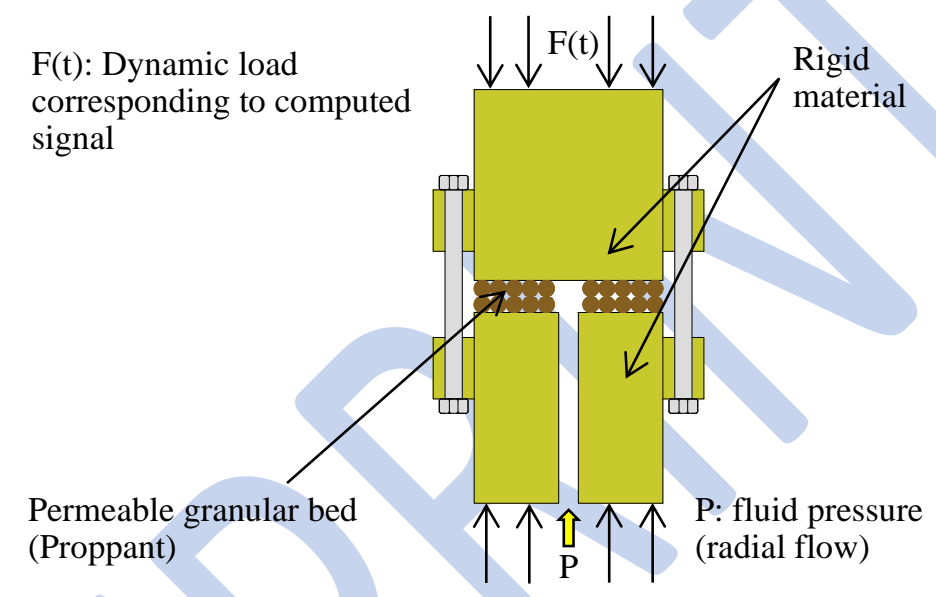

Fig. 3. Principle of the laboratory experiments. The fluid is injected at the bottom of the specimen and flows in the fracture horizontally. At the same time, an axial dynamic load is applied.

The experiments should make it possible to demonstrate the influence of various factors such as the proppant size, the dimensions of the clogging materials, frequency, amplitude, etc., on the unclogging process. Tests were carried out under vertical axial stress, which represents a fracture depth of $1600 \mathrm{~m}$ approximately. Lateral stresses were not applied, which means that we do not consider their effect on the possible unclogging. Such an effect would correspond to the relative motion of the crack faces, possibly due to a relief of the frictional forces induced by the dynamic load. It should be kept in mind that it may have some significative effect, a possible increase of the fracture aperture that would yield an increase of the fracture conductivity as well. 
In the following, we present the experimental setup developed to measure the permeability of a propped fracture at different stages of fracture exploitation (clean, clogged, and unclogged fracture). The properties of materials, the experimental procedure and the method of permeability measurements are presented as well. Freshwater and nitrogen gas were used to measure the permeability at ambient temperature under atmospheric pressure. In some tests, $\mathrm{x}$ ray micro CT scans have been used to map the positions of fine particles before and after applying the dynamic load.

\subsection{Specimen preparation}

Specimens were composed of two cylinders (Fig. 4) separated by a proppant layer. It is this proppant layer which mimics the fracture. The height and diameter of the cylinders are $50 \mathrm{~mm}$ and $46 \mathrm{~mm}$, respectively. The bottom one has a $6 \mathrm{~mm}$ centred borehole for fluid injection.

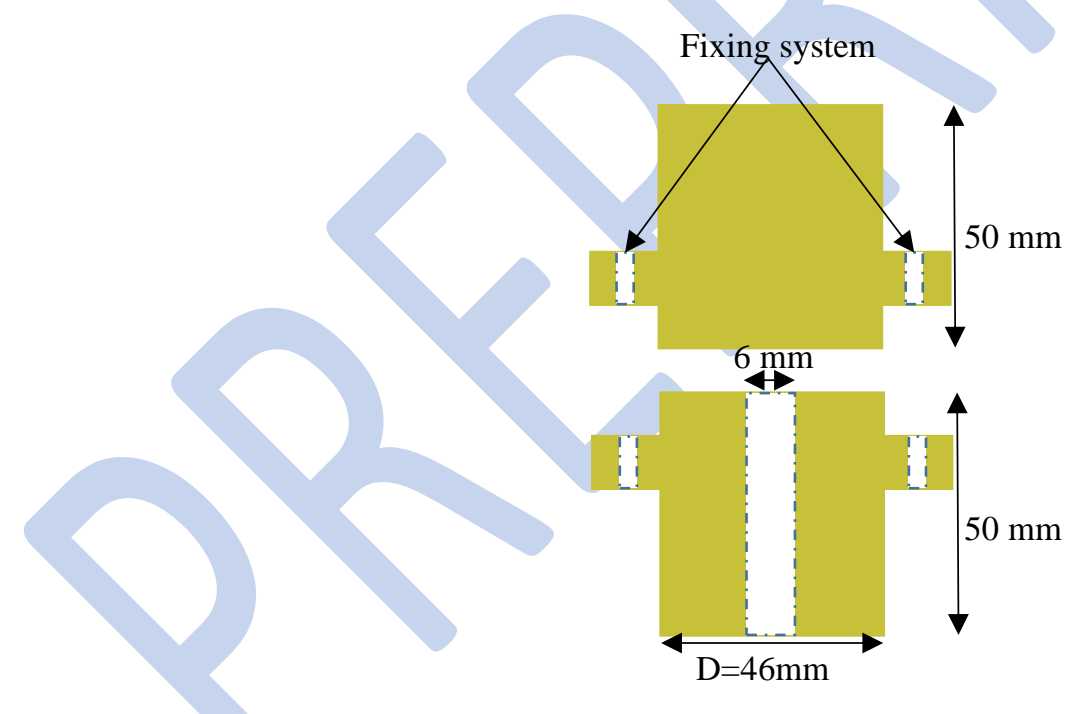

Fig. 4. Polycarbonate samples details.

The radial flow is ensured in the space left between the two cylinders. This space is filled with proppant, which represents the granular skeleton of a hydraulic propped fracture. All the tests were performed with cylinders made of polycarbonate and ceramic proppant. Polycarbonate being transparent to $\mathrm{X}$ rays, it was used instead of rock as it is easier to analyse CT scans and to visualize the proppant and the clogging fine particles. Besides, the mechanical properties of 
the rock surrounding the fracture are not at stake here, except those related to the embedment of proppant. Proppant embedment will be taken into account when measuring the effective fracture aperture. Mechanical tests performed on the polycarbonate sample showed that Young's Modulus and Poisson's ratio were 2.3 GPa and 0.34, respectively.

On the edge of each sample, a fixing system with four screw holes is provided to install later on four nylon threaded rods (M6 screw) with eight nuts (4 from each side). This fixing system is essential for avoiding any movement or change of the fracture configuration while the specimen is placed in the experimental set-up or transported to the CT scan facility.

Two ceramic proppant meshes were used to simulate the granular skeleton of the propped fracture. The main components of the proppant are mullite and silicon dioxide. The physical properties of the proppant used are detailed in Table 1 .

\begin{tabular}{|c|c|c|c|c|c|}
\hline US Mesh & $\begin{array}{c}\text { Specific } \\
\text { gravity }\end{array}$ & $\begin{array}{c}\text { Bulk density } \\
(\mathrm{g} / \mathrm{cc})\end{array}$ & $\begin{array}{c}\text { Median } \\
\text { diameter } \\
(\mathrm{mm})\end{array}$ & Dmin $(\mathrm{mm})$ & Dmax $(\mathrm{mm})$ \\
\hline Mesh 40/70 & $2.6-2.8$ & $1.4-1.6$ & 0.351 & 0.425 & 0.212 \\
\hline Mesh 30/50 & & 0.444 & 0.6 & 0.3 \\
\hline
\end{tabular}

Table 1 Physical properties of the proppant.

The distribution density of the proppant between the fracture walls is $361-630 \mathrm{~g} / \mathrm{m}^{2}$ for a single layer. This is the maximum density of proppant placed on a single uniform layer on a plane surface. In the foregoing, we shall measure the amount of proppant placed in the fracture with reference to this distribution density. Two layers of proppant mean therefore that the mass of proppant per unit surface put on the fracture is twice the distribution density. 


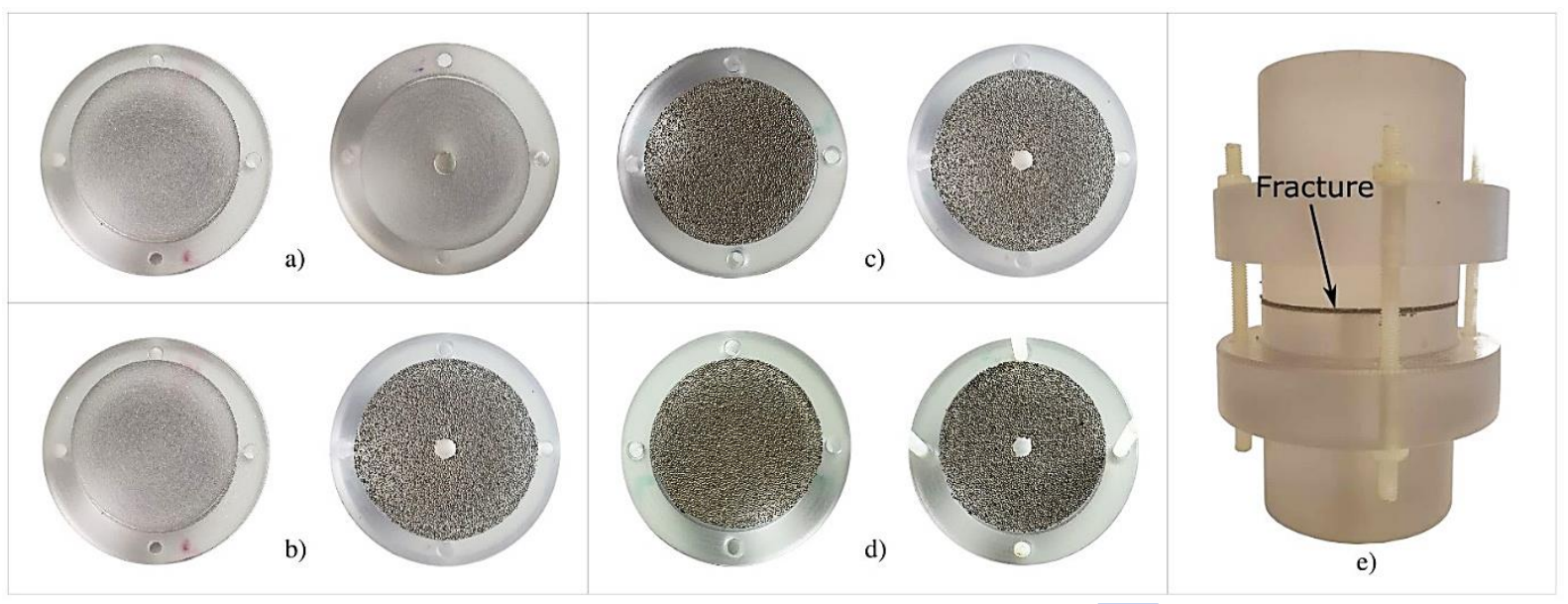

Fig. 5. Sample preparation procedure: a) two polycarbonate samples polished and cleaned; b) Single layer proppant distribution; c) Double layers proppant distribution; d) installing of Nylon rods; e) final polycarbonate fracture ready to be installed under the hydraulic frame.

Before placing the proppant particles, the total height of the specimen (polycarbonate samples together) is measured and denoted as $\mathrm{H}_{1}$. After that, the specimen is opened, and the required amount of proppant is placed (see Fig. 5). A natural soluble paste is spread on the top of the bottom sample (1 layer case) (Fig. 5b) and on both samples (2 layers case) (Fig. 5c) to stick the proppant grains to have a uniform distribution. We proceed then to close carefully the fracture by placing the two samples on each other and install the fixing system (Nylon rods and nuts). The nuts must be well screwed to avoid any movement or loss of the proppant grains. The new height of the specimen (samples+proppant) is then measured and denoted as $\mathrm{H}_{2}$.

Fig. 6 shows two photographs of the proppant layer placed in between the polycarbonate cylinders at different distribution densities. 

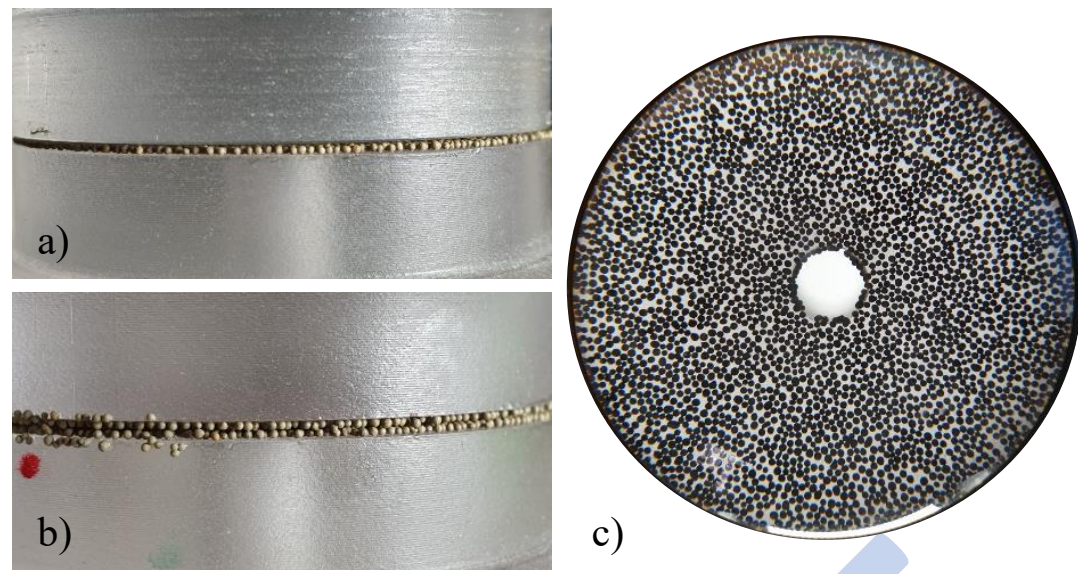

Fig. 6. Fracture configurations: a) side view of a fracture filled with a single layer of proppant; $b$ ) side view of a fracture filled with two layers of proppant; c) top view of a single layer of proppant.

There are many sources of fines that contribute to fracture clogging during well service life, such as proppant crushing, products of the chemical reaction between fluids and solids and matrix collapse due to creep. In this work, we clog the fracture with crushed natural sand with a diameter of particles ranging between $25 \mu \mathrm{m}$ and $75 \mu \mathrm{m}$. These fines are spread manually in the opened specimen after its initial permeability has been measured.

\subsection{Experimental set-up}

The experimental apparatus has been conceived mainly to measure the permeability of a propped fracture in different stages (clean, clogged, and unclogged) under a static load, as a geological constraint, and after a dynamic load. The design of the set-up is similar to a coreflooding system; it is described schematically in Fig. 7. 


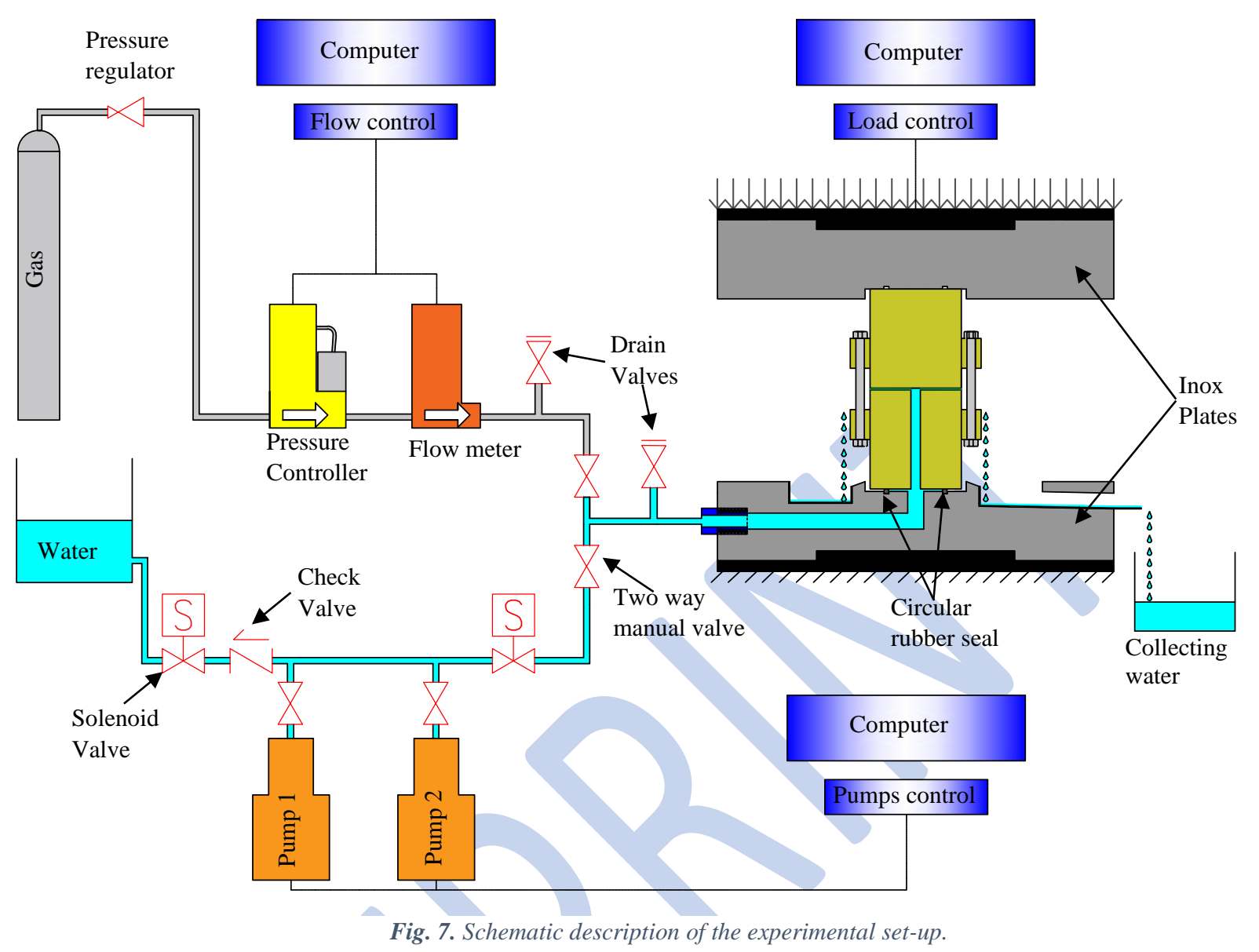

All the measurements of permeability were ensured using two different circuits with gas and water. The gas used in the permeability measurement is Nitrogen $\left(\mathrm{N}_{2}\right)$. The bottle is equipped with a manual pressure regulator to reduce the inlet pressure of the gas as desired. This circuit includes a mass flow meter with a capacity of $13.241 / \mathrm{min}$. The accuracy of the measurement is $+/-0.1 \%$ of the full scale (FS). A backpressure controller, with a capacity of 10 bars, controls the upstream pressure of the gas injected in the specimen. These devices are connected to a computer for measurements and controls.

Water injection is performed with the help of a second circuit, made of two pumps and two solenoid valves. The pump 1 is dedicated to measure water permeability with a low flow rate of $16.28 \mathrm{ml} / \mathrm{min}$ and to wash the fracture before starting the measurement of gas permeability (clean fracture without clogging). This pump is equipped with a Keller pressure transducer of 
10 bars and a Red Lion graphic operator interface to control the injection pressure, the injected volume, the flow rate, and the temperature.

The pump 2 is used mainly during the unclogging process while applying dynamic loads. The capacity of this pump is $240 \mathrm{ml} / \mathrm{min}$ of volumetric flow and 30 bars of maximum pressure. The injection and suction processes of the pumps are controlled remotely through a computer. Due to the non-reversibility of the solenoid valves, a check valve (non-return valve) is placed in the circuit to block the flow toward the water reservoir while injecting water in the specimen. These valves are controlled remotely too. Tubings, valves, and connections are made of corrosionresistant materials (Inox, Polyamide, and copper).

A servo-hydraulic uniaxial frame Zwick Roell HB250 is used to apply all static and dynamic uniaxial loads on the polycarbonate specimen containing the fracture using either displacement or force control. The permeability measurements are performed under static vertical stress of $20 \mathrm{MPa}(\mathrm{Load}=34 \mathrm{kN})$. The dynamic loads, applied during the unclogging process, are handled via the servo-hydraulic valve offering the highest hydraulic flow rate (64 1/min) with a wide range of dynamic waveforms, including sinusoidal, square, triangular, and trapezoidal.

\subsection{Testing procedure}

After the specimen has been prepared, it is placed in the uniaxial testing frame. The axial load is increased to $20 \mathrm{MPa}(34 \mathrm{kN})$ with a loading rate of $0.059 \mathrm{MPa} / \mathrm{s}(0.1 \mathrm{kN} / \mathrm{s})$. Once this stress is reached, a washing phase with two water injections is performed with pump 1 to clean out the paste used for the specimen preparation. Then, gas and water permeability are measured. The method for the measurement of the gas and liquid permeability is detailed in the next section. This procedure is repeated three times for each amount of proppant to have an average permeability. 
After having measured the water and gas permeabilities of a clean fracture, we start the clogging - unclogging experiments on new specimens as follow:

- $\quad$ Clog the fracture with crushed natural sand followed by permeability measurements: once the proppant is placed on the top of the samples (same procedure), different amounts of fines $(5,10,15 \%, \ldots)$ are spread manually on the bottom face of the fracture (Fig. 8). The weight of deposited fines is calculated as a percentage of the proppant weight placed inside the fracture. The mean diameter of the fine particles is about ten times less than that of proppant, so that electrostatic interactions between fine particles may be considered as negligible. The specimen is closed and we proceed to permeability measurements under the same axial load.

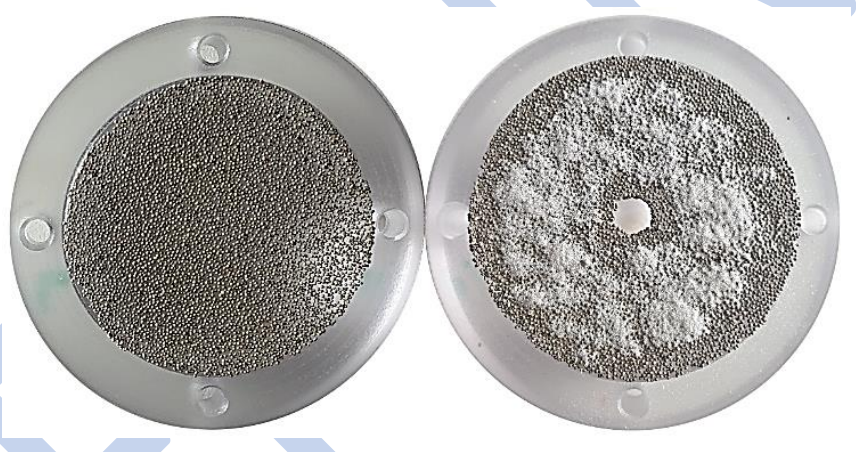

Fig. 8. Example of a fracture filled with 2 layers of proppant mesh $30 / 50$ and clogged with $25 \%$ of natural crushed sand (Fines present in white color on the right side).

- $\quad$ Once the permeability of the clogged fracture has been measured, we proceed to the application of dynamic uniaxial load. This synthetic signal is generated by the hydraulic uniaxial frame with a continuous injection of water, using pump 2 with a constant flow rate of $240 \mathrm{ml} / \mathrm{min}$. We used a square signal, with two amplitudes of $4.5 \mathrm{kN}$ and $9 \mathrm{kN}$, and two frequencies: $1 \mathrm{~Hz}, 10 \mathrm{~Hz}$. The oscillations of the injected water induced by the dynamic load help at flushing and transporting fines out of the fracture. It is intended to destabilize the aggregates of fines and to clean the fracture with a significant increase of the permeability. During this process, the water injection pressure might decrease, which means that the fracture conductivity is increasing. We stop the dynamic load when constant water pressure is reached. 
At this stage, the number of dynamic cycles (pulses) is recorded. The gas and water permeability are then measured again. Subsequently, the recovery rate is calculated based on the values of permeability measured in each stage: clean $\left(k_{\text {clean frac }}\right)$, clogged $\left(k_{\text {clogged frac }}\right)$, and unclogged fracture $\left(k_{\text {unclogged frac }}\right)$ :

$$
\text { Recovery rate }=\frac{k_{\text {unclogged } \text { frac }-k_{\text {clogged frac }}}}{k_{\text {clean } \text { frac }^{-} k_{\text {clogged frac }}}} \times 100
$$

In order to see the repeatability of the results, each test is repeated three times for each clogging percentage. At the end of each test, the specimen is removed from the permeability cell, and the new height $\mathrm{H}_{3}$ of the specimen is measured in order to see the effect of proppant embedment after the dynamic load has been applied.

X-ray CT scans were performed on some tests (after clogging and unclogging the fracture). It enables internal inspection of the fracture with a high resolution and in a non-destructive way. The submicron imaging system was an Xradia 510 Versa CT scanner with a 16-bit CCD detector, which is capable of acquiring radiographs with $2048 \times 2048$ pixels. The $\mathrm{X}$-ray source was set during the scans with a voltage of $100 \mathrm{kV}$ and a power of $9 \mathrm{~W}$. The acquisition parameters applied on the scans were the same for all the tests. They were selected and chosen in view of optimizing the image contrast, the signal-to-noise ratio of the projections, and the duration of the acquisition. The rotation step of the specimen was fixed at $0.18^{\circ}$, the exposure time was 4 seconds, and the voxel size was $18 \mu \mathrm{m}$ with a field of view of almost $37 \mathrm{~mm}$. The set of recorded radiographs was reconstructed with XRM Reconstructor@ (Zeiss, version 11) to obtain a stack of cross-sections forming a digital volume of the sample. The XCT data were processed, visualized and interpreted using Avizo® (FEI, Version 9.0.0). The data processing includes a filtering step to improve the signal-to-noise ratio and a subsequent segmentation step 
to extract 3 phases (pores, ceramic proppants, and fine particles). The same processing was applied to each data set so that the results are consistent between each other.

\subsection{Measurement of fracture permeability}

At the macroscopic scale, laminar flow (viscous flow) in a porous media is described by the well-known Darcy's law (Darcy 1856) which shows a linear relationship between the pressure gradient and the seepage velocity of the fluid. It is used to describe the flow in any fracture at low flow rates (Reynolds number $\operatorname{Re}<1$ ). This law assumes that viscous forces caused by fluids dominate over the inertial forces, which are negligible. For an incompressible fluid (like water) in a steady-state flow, this law can be represented in the following differential form:

$$
\overrightarrow{\mathrm{V}}=-\frac{\mathrm{K}_{\mathrm{in}}}{\mu} \overrightarrow{\mathrm{grad} P}
$$

where $\vec{v}$ is the seepage velocity $[\mathrm{m} / \mathrm{s}], \overrightarrow{\operatorname{gradP}}$ is the pressure gradient $[\mathrm{Pa} / \mathrm{m}], \mathrm{K}_{\text {in }}$ is the intrinsic permeability $\left[\mathrm{m}^{2}\right]$, and $\mu$ is the dynamic viscosity of the fluid [Pa.s].

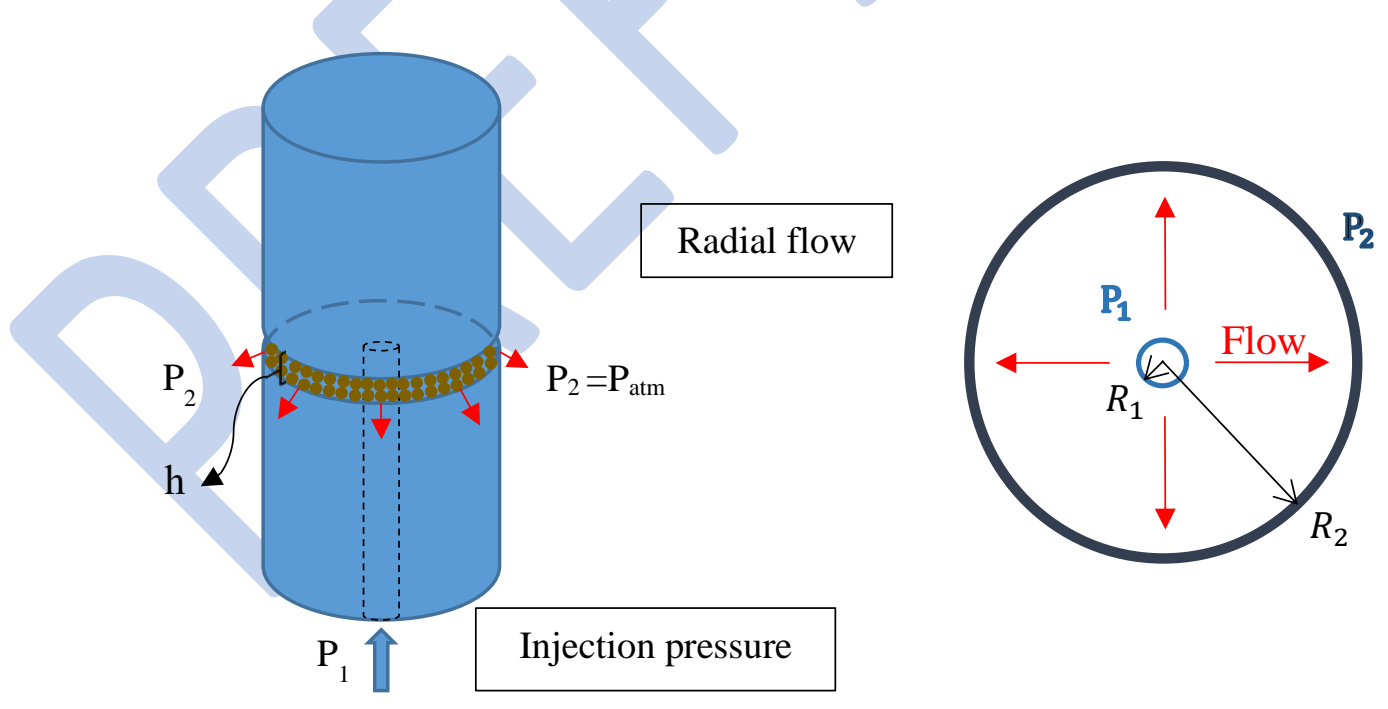

Fig. 9. Radial flow in the fracture.

For a radial flow (Fig. 9), the differential equation is integrated over the geometry of the fracture (radius of the inner borehole $=R_{1}$ and outer radius of the specimen $=R_{2}$ ). The intrinsic permeability measured with water $\mathrm{K}_{\mathrm{w}}\left[\mathrm{m}^{2}\right]$ at a low flow rates is computed directly. 


$$
\mathrm{K}_{\mathrm{W}}=\frac{\mu \ln \left(\frac{\mathrm{R}_{2}}{\mathrm{R}_{1}}\right) \mathrm{Q}}{2 \pi \mathrm{h}\left(\mathrm{P}_{1}-\mathrm{P}_{2}\right)}
$$

where the upstream flow rate $\mathrm{Q}\left[\mathrm{m}^{3} / \mathrm{s}\right]$ and the inlet pressure $\mathrm{P}_{1}$ are known, and the outlet pressure $P_{2}$ is the atmospheric pressure. $h$ is the fracture aperture [m].

For the (compressible) gas permeability, the mass balance equation needs to be considered in addition to Darcy's law to calculate the apparent gas permeability $\mathrm{K}_{\mathrm{aG}}\left[\mathrm{m}^{2}\right]$ :

$$
\mathrm{K}_{\mathrm{aG}}=\frac{\mu \ln \left(\frac{\mathrm{R}_{2}}{\mathrm{R}_{1}}\right) \mathrm{Q} \mathrm{P}_{2}}{\pi \mathrm{h}\left(\mathrm{P}_{1}^{2}-\mathrm{P}_{2}^{2}\right)}
$$

The relationship between the pressure gradient and the seepage velocity becomes non-linear. As the proppant has a high permeability, the fluid flow implies significant inertial forces, for gas especially. In our case, the inertial regime cannot be neglected because the Reynold's number ranges between $\sim 20$ and $\sim 100$ (Dybbs and Edwards, 1984). The Forchheimer correction is used to describe this inertial flow as a deviation of Darcy's law (Darcy non-linear extension, see e.g. Dullien, 1979). The equation of a monophasic flux through a porous media in a unidirectional flow is:

$$
-\frac{\mathrm{dp}}{\mathrm{dx}}=\frac{1}{\mathrm{~K}_{\mathrm{in}}} \mu v+\beta_{t} \rho v^{2}
$$


where $v$ is the uniaxial seepage velocity, $\frac{1}{\mathrm{~K}_{\mathrm{in}}} \mu v$ reflects the viscous effects (darcy's law), and $\beta_{t} \rho v^{2}$ the inertial effects. The latter is no longer negligible. $\beta_{t}$ is called the Forchheimer coefficient or inertial resistance coefficient, $\rho$ is the pressure-dependent fluid density $\left[\mathrm{kg} / \mathrm{m}^{3}\right]$ and $\mathrm{K}_{\mathrm{in}}$ is the intrinsic permeability. To develop the flux equation (5) for a compressible fluid (gas), we have applied the mass balance equation and the law of perfect gases with the consideration of an isothermal condition. The flux equation was then converted to a radial flow by integration on the cylindrical geometry $(x=R)$. The final equation shows the inverse of the apparent gas permeability as a function of the outgoing flow:

$$
\frac{1}{K_{a G}}=\left(\beta_{\mathrm{t}} \frac{M}{R T} \frac{\mathrm{P}_{2}}{\mu \mathrm{S}}\right) \mathrm{Q}+\frac{\Delta \mathrm{R}}{\mathrm{R}_{2} \ln \left(\mathrm{R}_{2} / \mathrm{R}_{1}\right) K_{\text {in }}}
$$

where $\mathrm{M}$ is the molar mass of the gas $[\mathrm{kg} / \mathrm{mol}], \mathrm{R}$ is the perfect gas constant $\left[\mathrm{J} \cdot \mathrm{K}^{-1} \cdot \mathrm{mol}^{-1}\right]$, $\mathrm{T}$ is the ambient temperature $\left[\mathrm{K}^{\circ}\right], \mathrm{S}$ the vertical surface of the fracture through which the fluid flows at $\mathrm{R}=\mathrm{R} 2\left[\mathrm{~m}^{2}\right]$. The intrinsic permeability $K_{\text {in }}$ is then determined by linear regression of the gas apparent permeability $K_{a G}$ measured at various injection pressures. Note that this intrinsic permeability is related to the porous skeleton of the fracture only. Therefore, it should be equal to the intrinsic permeability measured with water $\mathrm{K}_{\mathrm{w}}$.

The measurements of apparent permeability are performed with four relative pressures depending on the state of the fracture (clean, clogged, and unclogged). The relative pressures were: $0.1,0.2,0.3$, and 0.4 bars for a clean fracture (1 layers and 2 layers) and 0.2, 0.4, 0.6, 0.8, 1 bars for the clogged and unclogged fracture. The pressures were applied and maintained until gas flow stabilization. 
The main parameter to calculate the permeability is the fracture aperture. Recall that the height of the specimen was measured three times: $\mathrm{H}_{1}$ for the specimen without proppant, $\mathrm{H}_{2}$ for the specimen with proppant before loading and $\mathrm{H}_{3}$ at the end of the test, after the dynamic load has been applied. Let us denote $\mathrm{e}_{0}=\mathrm{H}_{2}-\mathrm{H}_{1}$ and $\mathrm{e}_{1}=\mathrm{H}_{3}-\mathrm{H}_{1}$ the apertures measured before and after the tests respectively. Table 2 shows the recorded values:

\begin{tabular}{|c|c|c|}
\hline & $\mathrm{e}_{0}(\mathrm{~mm})$ & $\mathrm{e}_{1}(\mathrm{~mm})$ \\
\hline 1 layer 40/70 & 0.44 & 0.29 \\
\hline 2 layers 4070 & 0.69 & 0.58 \\
\hline 2 layers 30/50 & 1.04 & 0.90 \\
\hline
\end{tabular}

Table 2 Average fracture opening before $\left(e_{0}\right)$ and after $\left(e_{1}\right)$ the test.

The difference between these two apertures is mainly due to proppant embedment (which is significative considering that the hardness of polycarbonate is much less than the hardness of rocks). $e_{1}$ is the fracture aperture that will be used to calculate the permeability $\left(e_{1}=h\right)$.

In order to make sure that the final fracture aperture $\mathrm{e}_{1}$ is indeed the fracture aperture, even after the dynamic loads have been applied, additional mechanical tests have been performed. The first test was performed only on two polycarbonate samples, and the second was carried out with one layer of proppant $40 / 70$. The load was increased up to $45 \mathrm{kN}$, above the maximum load applied during the dynamic phase of the test. The proppant embedment was obtained then by subtracting polycarbonate and the system (Machine+plates) deformations recorded between these two tests. As shown in Fig. 10, the embedment is about $0.18 \mathrm{~mm}$ when the load increases from 0 to $45 \mathrm{kN}$. This value stays almost constant during unloading (from 45 to $10 \mathrm{kN}$ ). It means that the embedment is mostly due to local plastic deformation of polycarbonate that occurs after the load has reached a maximum. The fracture aperture measured at the end of the test (after unloading) is representative of the fracture aperture for the cleaned, clogged, and 
unclogged configurations, once the load has been applied and plastic deformations occurred. Besides, the assumption that proppant deformation is negligible is true due to the high stiffness of the proppant (Mullite, E=91 GPa) compared to Polycarbonate $(\mathrm{E}=2.2 \mathrm{GPa})$. The permeability of the clean and clogged fracture is measured prior to applying the dynamic loads. Dynamic loads induce an incremental embedment compared to that, due to static loads, which is accounted for in the calculations of these permeabilities. It follows that they are slightly underestimated (5\% typically). This slight variation is neglected.

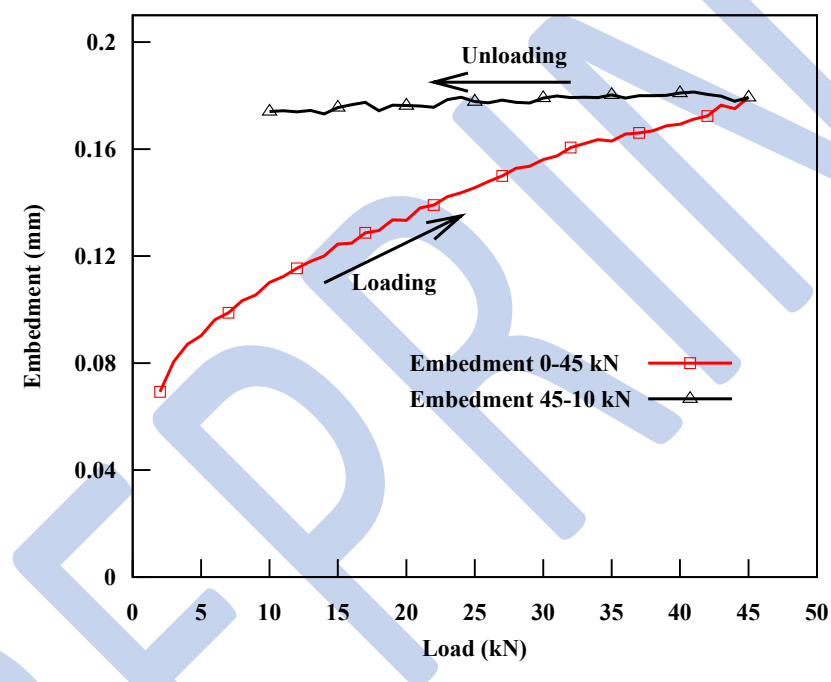

Fig. 10. Proppant embedment in a fracture filled with 1 layer (proppant mesh 40/70).

\section{Experimental results}

In this section, the evolution of permeability is reported with various clogged fractures after applying a dynamic load. The parameters discussed are fines percentages, proppant sizes (different meshes), and frequencies. Prior to that, tests with X-Ray CT scans are presented for two different cases of proppant to see the effect of this stimulation on the mobilization of fine particles. 


\subsection{Tests with X-Ray CT scans}

Two tests have been performed with one and two layers of proppant. For each case, we show X-Ray micro CT scans of the fracture clogged and unclogged (after applying the dynamic load), along with the evolution of the fracture permeability.

Let us first consider tests with 2 layers of proppant (Mesh 40/70). The average initial permeability of a clean fracture filled with two layers of proppant is $56 \mathrm{Da}$. The fracture is then clogged with $15 \%$ of fine particles followed by a permeability measurement (11 Da). The value of permeability decreases by $80 \%$ of the initial one. The fracture is then subjected to a dynamic load (square signal) with a frequency of $10 \mathrm{~Hz}$ and amplitude $9 \mathrm{kN}(5.4 \mathrm{MPa})$. Fig. 11 shows the evolution of the fracture permeability during the application of the dynamic load with a constant water flow rate injection. A sudden increase in the fracture permeability is observed when the dynamic load is applied. We observe here a recovery rate of $75 \%$.

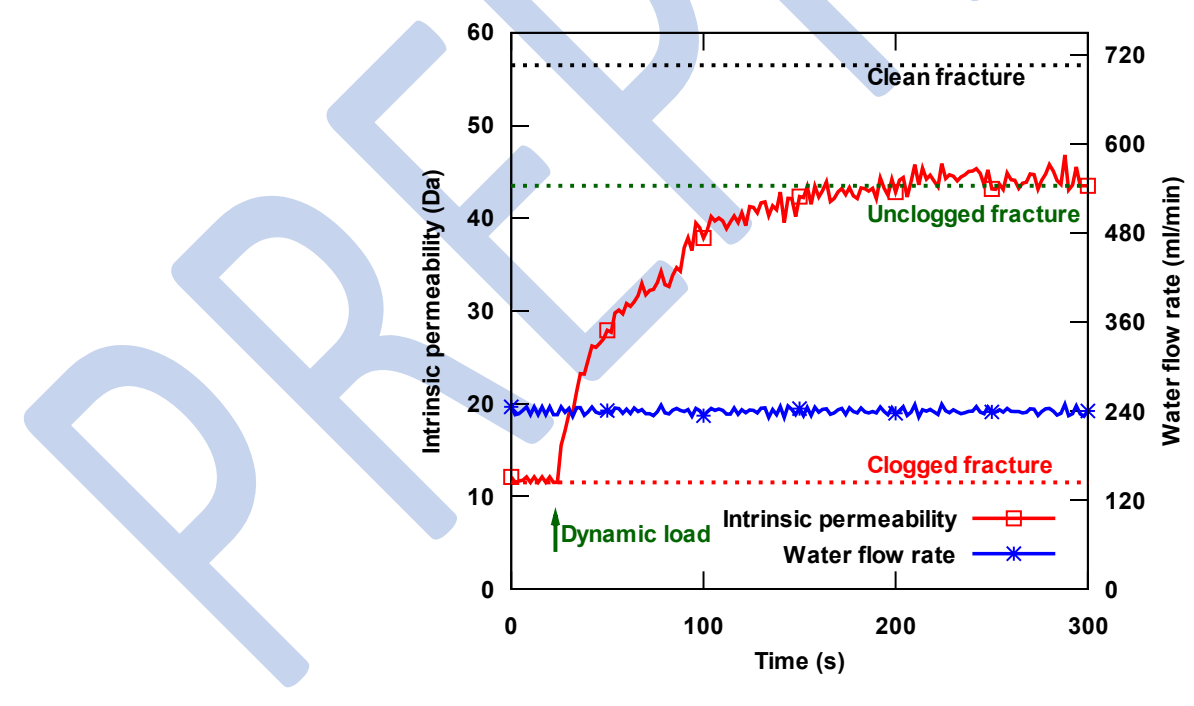

Fig. 11. Evolution of the intrinsic permeability in a clogged fracture filled with 2 layers of proppant during the application of a dynamic load $(f=10 \mathrm{~Hz}, A=5.4 \mathrm{MPa})$.

CT scans in Fig. 12 show that the fracture is almost cleaned from fine particles after the dynamic stimulation. There is a loss of $81 \%$ of fine particles. 

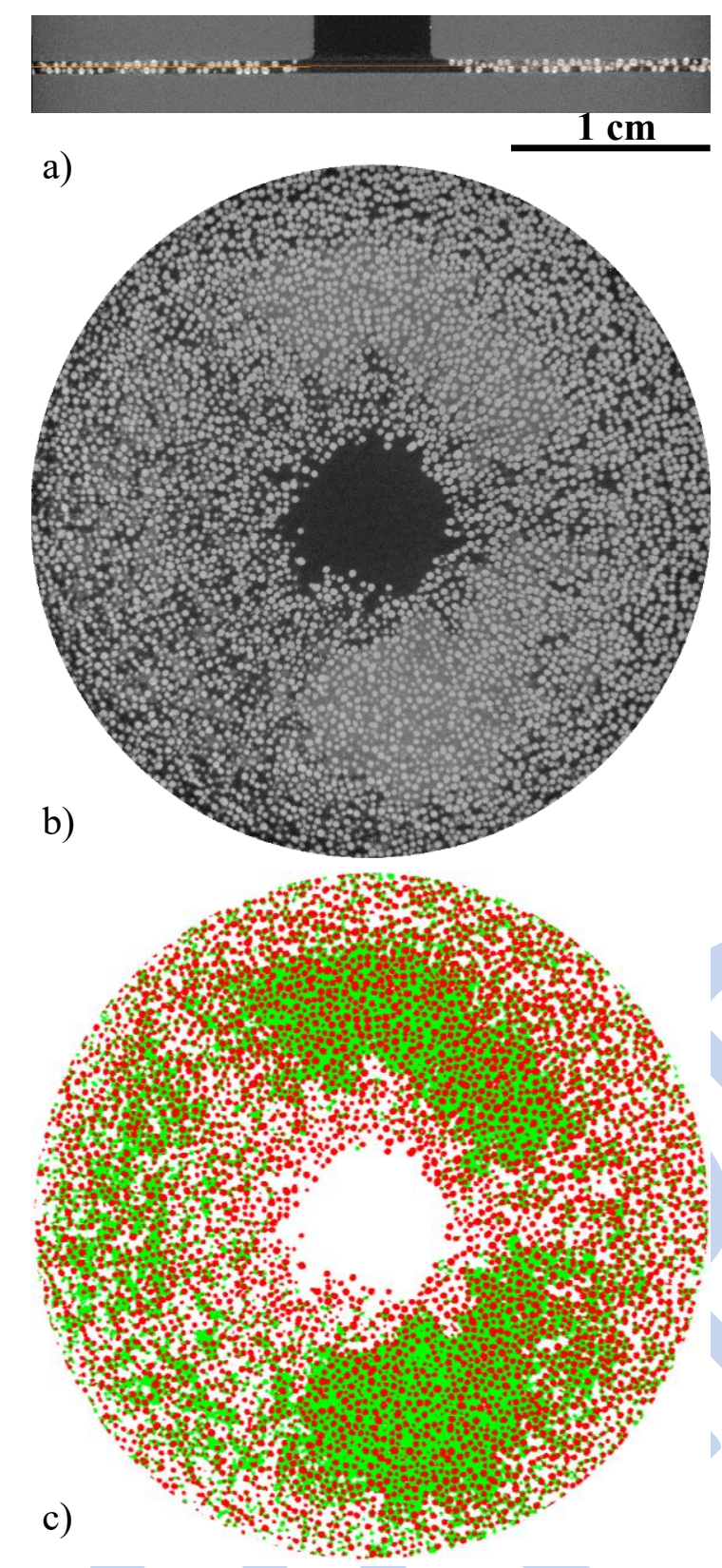

Fig. 12. X-ray images for a scanned clogged fracture with two layers of proppant before $(a, b, c)$ and after applying the dynamic load $(d, e, f):(a, d)$ cross-sections of the fracture showing two layers of proppant; $(b, e)$ original images of transverse sections of the fracture; $(c, f)$ segmented transverse sections. Proppant particles are in red and fine particles are in green.

In the case of a single layer of proppant, the average intrinsic permeability measured on a clean fracture filled with one layer is 54 Da. $10 \%$ of fine particles (crushed natural sand) is placed in the fracture. After two water injections, gas permeability is measured (12 Da); it represents a decrease of $77 \%$ of the fracture conductivity. The fracture is then subjected to a dynamic stimulation with a square signal, with the same characteristics as for the case of two layers of proppant. The evolution of the intrinsic permeability with constant water injection $(240 \mathrm{ml} / \mathrm{min})$ 
during the dynamic stimulation is plotted in Fig. 13. In this case, an additional decrease of permeability is observed until it reaches $8 \mathrm{Da}$.

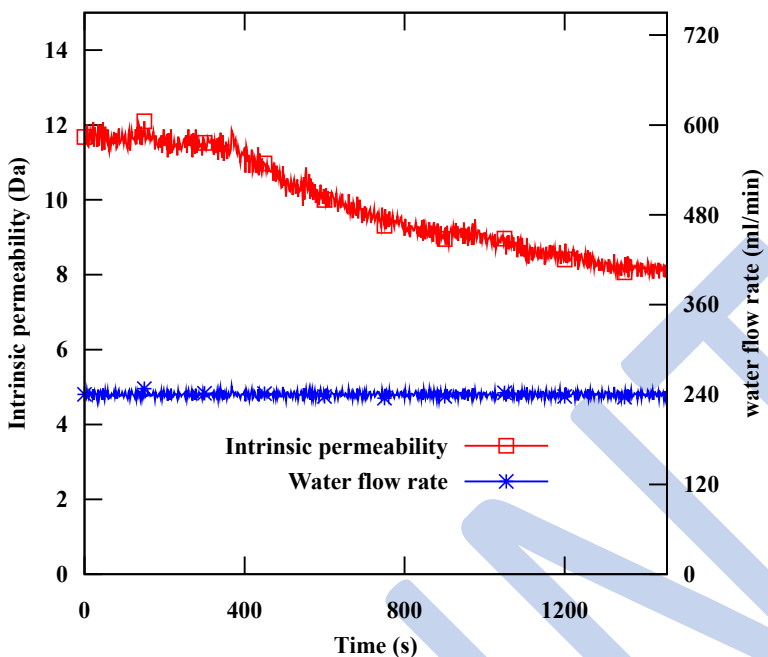

Fig. 13. Evolution of the intrinsic permeability in a clogged fracture filled with 1 layer of proppant during the application of a dynamic load $(10 \mathrm{~Hz}, 5.4 \mathrm{MPa})$.

To understand the result, which is at the opposite of the previous one, we may again look at CT scans (Fig. 14). The comparison between Fig. 14c and Fig. 14f shows that a large amount of fine particles $(51 \%)$ has migrated after the application of the dynamic signal. In addition, we may also observe in Fig. 14f the formation of arched aggregates of fine particles, which plays a significant role in decreasing the permeability of the fracture. Cumulating these arched aggregates will form a complete circle of aggregates, which serves as a barrier for the fluid flow. This test was repeated several times, also with a lower percentage of clogging materials, and it yielded the same results. 

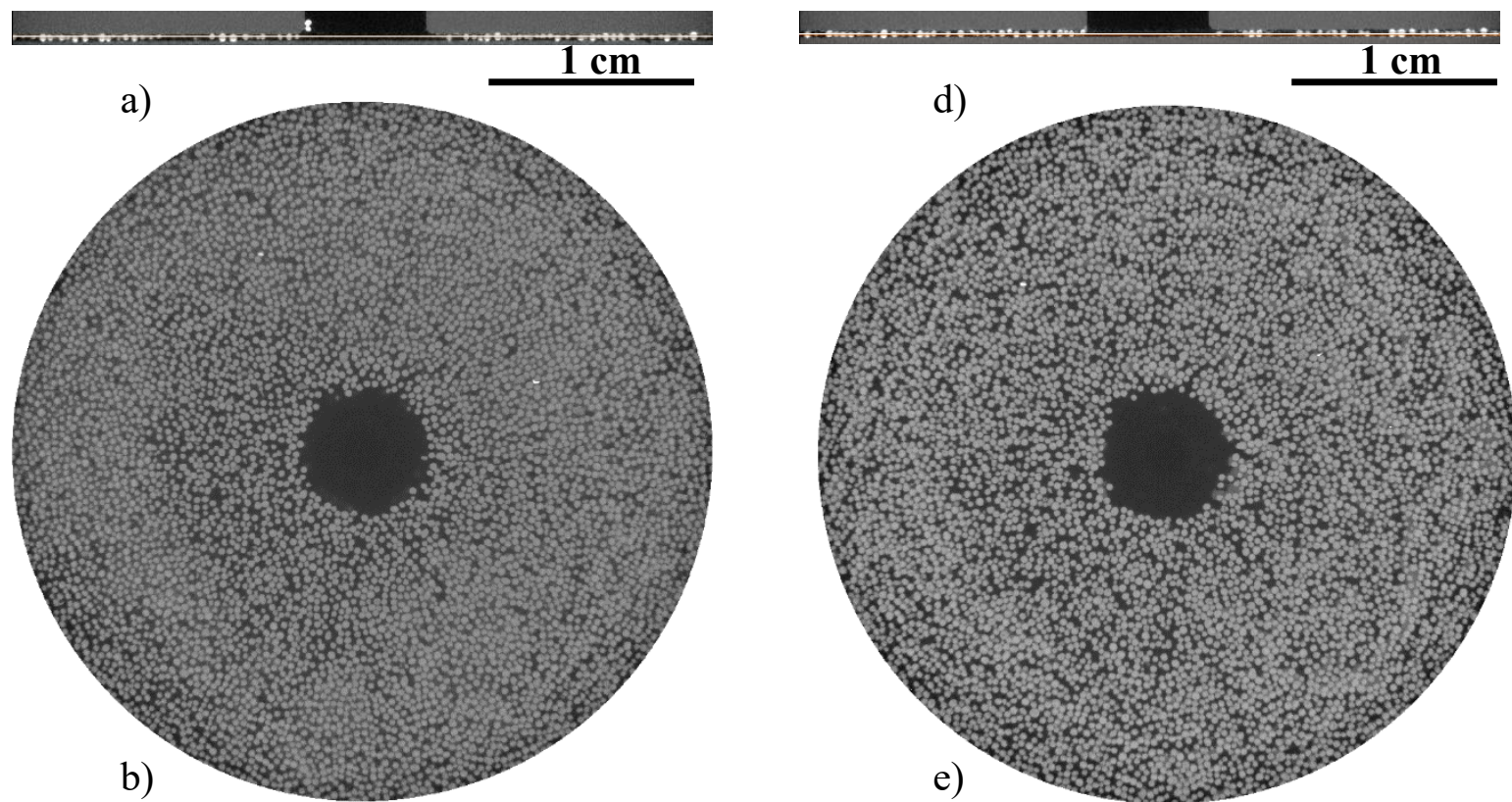

b)
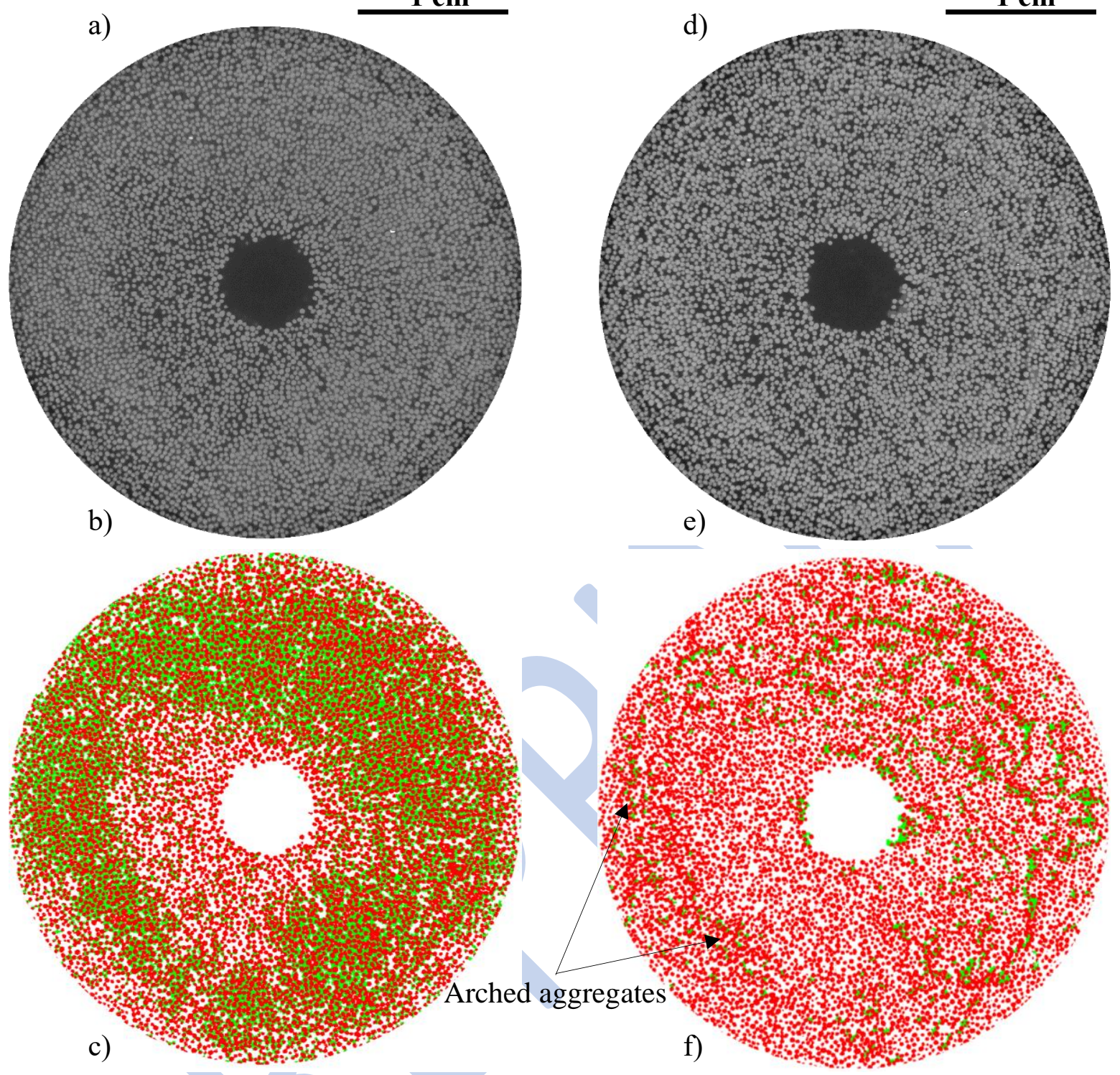

Fig. 14. X-ray images for a scanned clogged fracture before $(a, b, c)$ and after $(d, e, f)$ applying the dynamic load: $(a, d)$ cross sections of the fracture showing one layer of proppant; $(b, e)$ original images of transverse sections of the fracture; $(c, f)$ segmented transverse sections. Proppant particles are in red and fine particles are in green.

The primary reason behind the formation of the arched aggregates of fine particles is the decrease of the hydraulic diameter observed in the one layer configuration of proppant, which is, in fact rather peculiar. Fig. 15 shows a conceptual description of how the proppant embedment can affect the fluid flow using two grains of proppant with a median diameter $(\mathrm{dm}=340 \mu \mathrm{m})$. The hydraulic diameter after embedment can reach $\mathrm{d}=\mathrm{d}_{\mathrm{m}} / 6=56 \mu \mathrm{m}$, which restricts the flow of fines with a diameter greater than $56 \mu \mathrm{m}$ (fines range between $25-75 \mu \mathrm{m}$ ). 
Therefore, fines might block the flow path inside pores which allow arch clustering of fine particles.

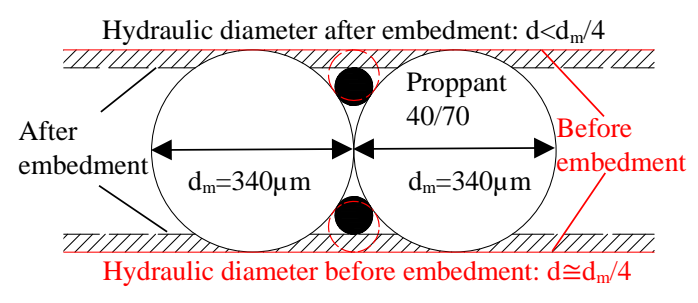

Fig. 15. Effects of the embedment on the fracture conductivity and its aperture.

Such a reduction of the hydraulic diameter is much less pregnant when several layers of proppant are considered, the decrease being of concern for the pores whose walls are the fracture surfaces. This may explain why the recovery rate in the case of two layers is positive, while it is negative in the case of a single layer.

Tests have been performed for distributions of proppant ranging from 0.5 layers to 2 layers (Fig. 16). The amount of fine particles ranged from 5\% to $15 \%$. In these tests, the dynamic load was a sinusoidal signal with amplitude $9 \mathrm{kN}$ and frequency $10 \mathrm{~Hz}$. We observe that the configuration of 1 layer of proppant minimizes the effect of the dynamic stimulation. For 0.5 layers, the hydraulic diameter is not strongly affected by embedment because the distribution of proppant particles is sparse. A moderate recovery is obtained; it increases a lot for the case of two layers of proppant. 


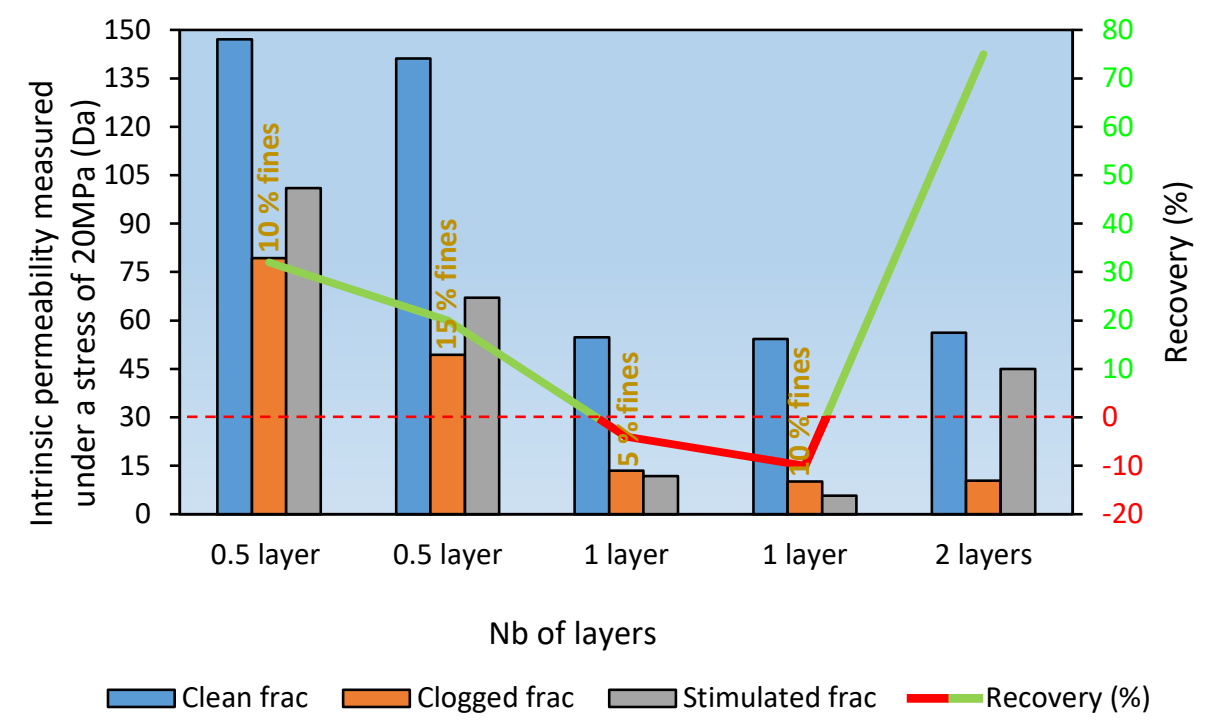

Fig. 16. Effects of the number of layers of proppant on the recovery of permeability.

\subsection{Influence of the proppant size}

In order to investigate the effect of the proppant size, experiments have been performed in the case of two layers of proppant and with a square dynamic signal with frequency $1 \mathrm{~Hz}$. Two tests for each mesh were carried out: fractures with $30 / 50$ mesh clogged with $25 \%$ of fines and fractures with $40 / 70$ mesh clogged with $15 \%$ of fines. The evolution of the intrinsic permeability of each fracture with the number of applied pulses is shown in Fig. 17. The average intrinsic permeability of a clean fracture filled with two layers of $30 / 50$ proppant mesh is 62.5 $\mathrm{Da}$. The ranges of the intrinsic permeability for the clogged fractures with $15 \%$ and $25 \%$ are 9 $11 \mathrm{Da}$ and 2.5-3.5 Da, respectively. During the application of the dynamic load, the permeability of the clogged fractures increases with the number of pulses. Two different kinetics of permeability recovery are identified; the first one is in 30/50 fractures where the permeability increases sharply and reaches 45-52 Da with 118-150 pulses, whereas the second one is in the 40/70 fractures where the permeability increases gradually and reaches $24-27 \mathrm{Da}$ with more than 400 pulses. The recovery rates reached in this series are 82\% (30/50) and 36\% 
(40/70). The comparison between these two meshes shows that the larger the proppant diameter, the faster the unclogging process.

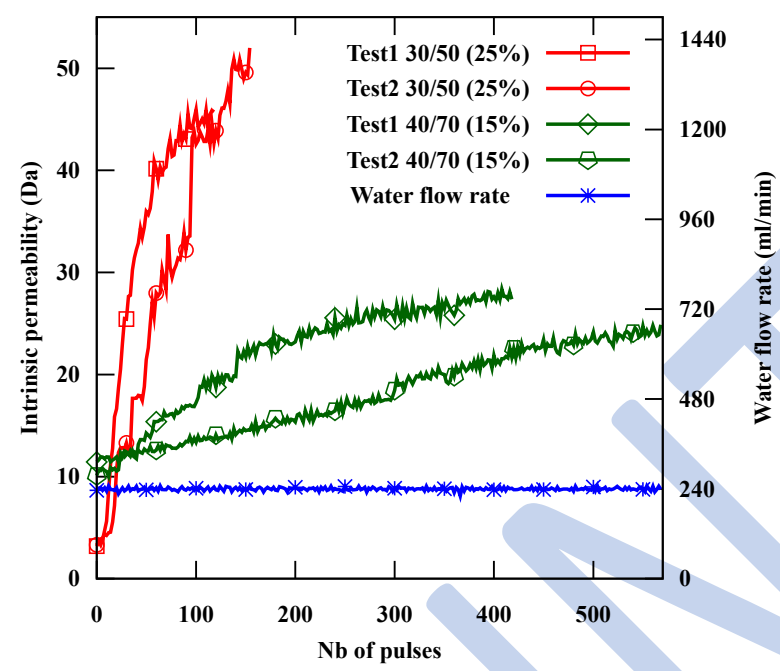

Fig. 17. Evolution of the intrinsic permeability of 4 clogged fractures (15\% and $25 \%$ of fines) filled with 2 layers of proppant (different meshes) during the application of a dynamic load $(f=1 \mathrm{~Hz}, \mathrm{~A}=5.4 \mathrm{MPa}$ ).

\subsection{Influence of frequency of the dynamic signal}

A clogged fracture (20\% of fines) filled with two layers of proppant (40/70) was subjected to a dynamic square signal with two different frequencies: $1 \mathrm{~Hz}$ at first, and then $10 \mathrm{~Hz}$. The amplitude of the signal is constant $\mathrm{A}=5.4 \mathrm{MPa}$. The evolution of the intrinsic permeability during the dynamic stimulation is plotted in Fig. 18. Two different regimes can be observed; when the frequency of the dynamic load applied is $1 \mathrm{~Hz}$, the permeability of the fracture increases slightly until it reaches 4.7 Da. Once the frequency of the dynamic load is switched to $10 \mathrm{~Hz}$, the permeability increases sharply to $6.4 \mathrm{Da}$. Therefore, increasing the frequency accelerates the unclogging process.

The recovery rate for the amount of fine considered remained small $(4 \%)$ in the first phase of the test. Following many performed tests, a percentage of fine of $20 \%$ was found to be high for 
a fracture filled with 2 layers of proppant, especially with a mesh of 40/70. Such clogged fractures can be unclogged only with a dynamic load with a frequency higher than $1 \mathrm{~Hz}$.

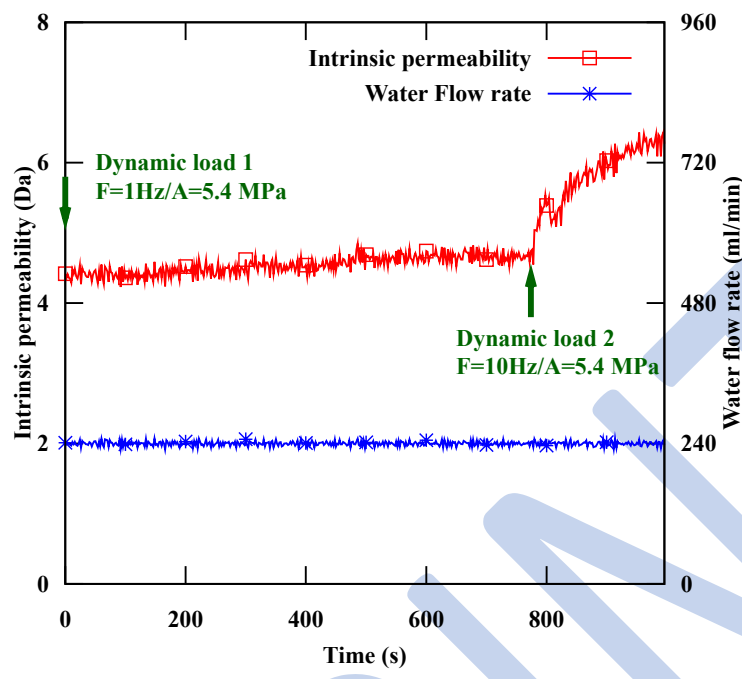

Fig. 18. Effects of the frequency on the unclogging process (2 layers fracture $40 / 70$ clogged with $20 \%$ of fines).

Four tests with $35 \%$ of fines were carried out with two layers of proppant mesh $30 / 50$. The fractures were then subjected to a dynamic load with a frequency of $1 \mathrm{~Hz}$ ( 2 tests) and $10 \mathrm{~Hz}$ (2 tests). All the tests were done with an amplitude of 2.7 MPa. The evolution of the intrinsic permeability of each test with the number of pulses is shown in Fig. 19.

The initial permeability of these clogged fractures ranges between $1 \mathrm{Da}$ and $2 \mathrm{Da}$. For the fractures subjected to $10 \mathrm{~Hz}$, the permeability increases slightly to $4 \mathrm{Da}$ with 400 pulses; then it increases sharply until reaching $26 \mathrm{Da}-28 \mathrm{Da}$ after 1000 pulses with a recovery rate ranging between $40 \%$ and $44 \%$. For the fracture subjected to $1 \mathrm{~Hz}$, the permeability stayed almost constant with the first 420 pulses, and then increased gradually to reach 6.6 Da-8.4 Da, with a less recovery rate of $7 \%-12 \%$, after $950-990$ pulses.

These tests show the importance of the frequency of the dynamic load on the unclogging process. It is reflected through the tests performed with $10 \mathrm{~Hz}$, where the recovery rate was 3 
to 5 times higher than the tests performed with $1 \mathrm{~Hz}$. At the same time, the number of pulses applied is important as there is a threshold below which the permeability stays constant.

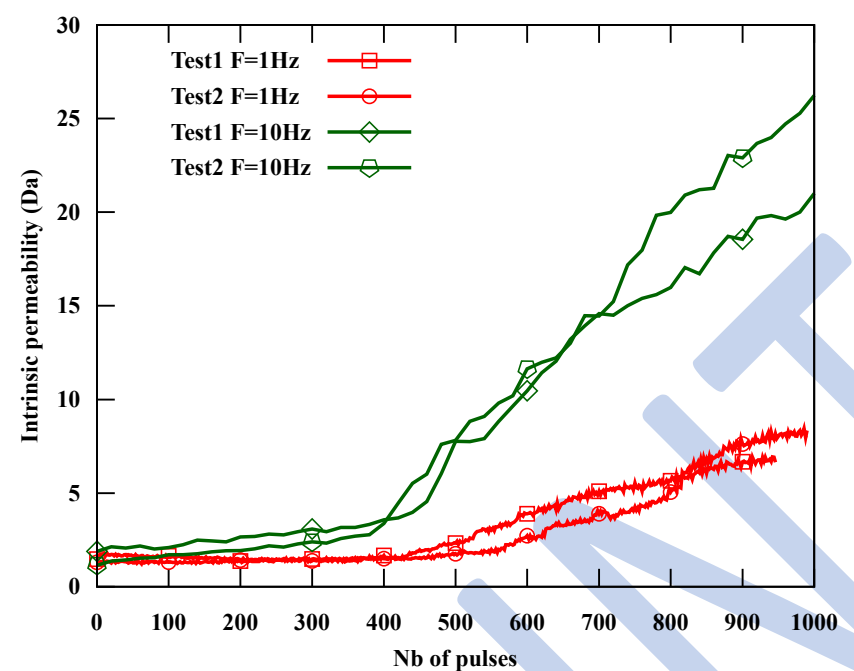

Fig. 19. Evolution of the intrinsic permeability of 4 clogged fractures (35\% of fines) with 2 layers of proppant (mesh

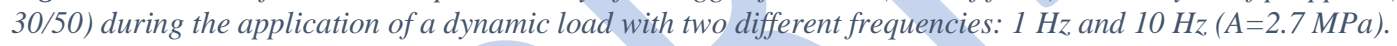

\section{Conclusion}

During well service, fluids and gases cause fine particles to circulate in the fractures. These fine particles can adhere to the crack walls and the proppant skeleton, and may form clusters or aggregates which clog pore throats. Consequently, the conductivity of propped fracture decreases due to the accumulation of these fine particles. We have presented an experimental study aimed at exploring the effect of dynamic oscillations of fluid pressure inside a propped fracture on its conductivity. It is envisioned that such pressure oscillations would result from the propagation of surface wave on the fracture that generate a variation of the fracture aperture. The experimental set-up designed for this study allows the measurement of the permeability (gas and water) of a cleaned fracture, then fines are added in the fracture which decreases the conductivity. The specimen being placed in a uniaxial testing machine, a dynamic load is 
applied and the evolution of the conductivity of the fracture is measured with the number of pulses applied during the test.

Conclusions of the testing program are as follow:

- With a proppant density of 2 layers, unclogging has been observed with a recovery rate reaching $75 \%$ for $40 / 70$ proppant and higher than $82 \%$ for $30 / 50$ proppant.

- The unclogging process failed to take place with a proppant density of 1 layer, although a loss of $51 \%$ of fine particles has been observed. In this case arched aggregates of fine particles formed, leading to subsequent fracture clogging. A density of 1 layer is expected to be a special case where the proppant embedment has a severe influence on the hydraulic diameter of the pore in the fracture. Tests with increased density of proppant (0.5 layers, 1 layer, 2 layers) show that the one layer case is a minimum in the recovery of the fracture conductivity.

- Proppant size has an influence on the unclogging response; the permeability increases when the proppant diameter increases. The kinetics of unclogging is also faster as the proppant size increases.

- The frequency of the signal also plays an essential role in the speed of the unclogging process and thus on the mobilization of fines. Fractures subjected to a dynamic load with a higher frequency $(10 \mathrm{~Hz})$ led to more significant recovery rates than the ones subjected to a lower frequency $(1 \mathrm{~Hz})$, especially in a highly clogged fracture.

\section{Acknowledgements}

Financial support from Total E\&P is gratefully acknowledged. X-ray micro CT scans have been provided and analyzed by the E2S UPPA-DMEX centre for X-ray imaging. The authors would like to thank Total for providing UMS 3360 DMEX with the Zeiss Xradia Versa 510T used to carry out the tomographic acquisitions reported in this article. 


\section{References}

Beresnev, A., Johnson, P.A., 1994. Elastic-wave stimulation of oil production: A review of methods and results, Geophysics, 59, 1000-1017.

Brodsky, E.E., 2003. A mechanism for sustained groundwater pressure changes induced by distant earthquakes. J. Geophys. Res. 108, 1-10. https://doi.org/10.1029/2002jb002321

Candela, T., Brodsky, E.E., Marone, C., Elsworth, D., 2014. Laboratory evidence for particle mobilization as a mechanism for permeability enhancement via dynamic stressing. Earth Planet. Sci. Lett. 392, 279-291. https://doi.org/10.1016/j.epsl.2014.02.025

Chen, W., Maurel, O., Reess, T., Sylvestre de Ferron, A., La Borderie, C., Pijaudier-Cabot, G., Rey-Betbeder, F., Jacques, A. 2012. Experimental Study on an Alternative Oil Stimulation Technique for Tight Gas Reservoirs Based on Dynamic Shock Waves Generated by Pulsed Arc Electrohydraulic Discharges, J. Petroleum Science and Engrg., 88-89, 67-74.

Darcy H (1856) Les Fontaines Publiques de la Ville de Dijon [The Public Fountains of the City of Dijon]. Dalmont, Paris, France.

Dullien, F.A.L., 1979, Porous media, Fluid transport and pore structure , Academic press, London, U.K.

Dybbs, A., Edwards, R. V., 1984. A New Look at Porous Media Fluid Mechanics — Darcy to Turbulent. Fundam. Transp. Phenom. Porous Media 199-256. https://doi.org/10.1007/ 978-94-009-6175-3_4

Elkhoury, J.E., Niemeijer, A., Brodsky, E.E., Marone, C., 2011. Laboratory observations of permeability enhancement by fluid pressure oscillation of in situ fractured rock. J. Geophys. Res. Solid Earth 116, 1-15. https://doi.org/10.1029/2010JB007759

Guerra, J., Zhu, D., Hill, A.D., 2018. Impairment of fracture conductivity in the eagle ford shale formation. SPE Prod. Oper. 33, 637-653. https://doi.org/10.2118/184857-MS

Kennedy, R., 2015. Gas Shale Challenges Over the Asset Life Cycle. Fundamentals of Gas Shale Reservoirs, Ed. by R. Rezaee, Wiley Pubs, Chapt. 17, https://doi.org/10.1002/9781119039228.

Liu, Q., Zhao, B., Santamarina, J.C., 2019. Particle Migration and Clogging in Porous Media: A Convergent Flow Microfluidics Study. J. Geophys. Res. Solid Earth 124, 9495-9504. 
https://doi.org/10.1029/2019JB017813

Nicolas, A., Garcimartín, Á., Zuriguel, I., 2018. Trap Model for Clogging and Unclogging in Granular Hopper Flows. Phys. Rev. Lett. 120, 1-7. https://doi.org/10.1103/PhysRevLett. 120.198002

Pijaudier-Cabot, G., La Borderie, C., Reess, T., Chen, W., Maurela, O., Rey-Bethbeder, F., de Ferron, A., 2016. Electrohydraulic fracturing of rocks, ISTE-Wiley, UK.

Roberts, P.M., 2005. Laboratory observations of altered porous fluid flow behavior in berea sandstone induced by low-frequency dynamic stress stimulation. Acoust. Phys. 51, 160168. https://doi.org/10.1134/1.2133962

Varela-Valdez, A., La Borderie, C., Pijaudier-Cabot, G., 2017. Propagation of a fluid pressure wave through a rock fracture. Final report to Total E\&P, Université de Pau et des Pays de l'Adour, France.

Zheng, X.L., Shan, B.B., Chen, L., Sun, Y.W., Zhang, S.H., 2014. Attachment-detachment dynamics of suspended particle in porous media: Experiment and modeling. J. Hydrol. 511, 199-204. https://doi.org/10.1016/j.jhydrol.2014.01.039

Zhong, Y., Kuru, E., Zhang, H., Kuang, J., She, J., 2019. Effect of Fracturing Fluid/Shale Rock Interaction on the Rock Physical and Mechanical Properties, the Proppant Embedment Depth and the Fracture Conductivity. Rock Mech. Rock Eng. 52, 1011-1022. https://doi.org/10.1007/s00603-018-1658-z 